\title{
Multiple sclerosis, tropical spastic paraparesis and HTLV-1 infection in Afro-Caribbean patients in the United Kingdom
}

\author{
Peter Rudge, Amza Ali, J K Cruickshank
}

\begin{abstract}
Forty four consecutive patients of AfroCaribbean origin resident in the United Kingdom (UK) were studied, based on a provisional diagnosis of myelopathy of unknown cause, tropical spastic paraparesis (TSP) or multiple sclerosis (MS). Of 30 patients with progressive paraparesis 27 had serum antibodies to HTLV-1 and were classified as having TSP. Fourteen patients fulfilled the criteria for $M S$ and none of 12 tested had HTLV-1 antibodies. All the TSP patients and nine of those with MS were born in the West Indies. Five of the West Indianborn MS patients had migrated to the UK after adolescence but the duration of residence in the $U K$ before symptoms of MS developed was similar to those born in the UK (average 18 years). The features that differentiated MS from TSP patients, apart from HTLV-1 status, included clinical evidence of cranial nerve involvement, more extensive abnormalities on the brain and cervical cord MRI and asymmetry of the VEP latency increase, all of which were more frequent in the MS group. Of the three patients without a diagnosis one, born in the UK, had marked abnormalities on MRI of the brain indistinguishable from those seen in MS.
\end{abstract}

Tropical spastic paraparesis (TSP), a demyelinating and degenerative myelopathy associated with, and probably caused by the human $\mathrm{T}$-cell lymphotropic type-1 (HTLV-1) retrovirus, ${ }^{1}$ is common in the Caribbean, ${ }^{23}$ continental South America, particularly in the tropical and subtropical areas, ${ }^{4}$ Japan, ${ }^{5}$ parts of Africa ${ }^{67}$ and a number of tropical islands, for example, the Seychelles. ${ }^{8}$ It also occurs in emigrants from these areas, especially the Caribbean, to Europe, notably France ${ }^{9}$ and the United Kingdom, ${ }^{1011}$ and to the USA. Multiple sclerosis (MS) is a demyelinating disorder of unknown aetiology found principally in the temperate zones and thought to be rare in the Caribbean. ${ }^{12}$ The prevalence of MS in the UK is high in the indigenous white population, for example, for London $115 / 10^{5},{ }^{13}$ and there have been suggestions that people of Caribbean descent born in the UK have a similar prevalence of MS. ${ }^{1415}$ In contrast it is said that immigrants from the Caribbean have a low incidence of $M S^{16}$ and many neurologists believe that age at immigration is critical in determining the development of the disease since Dean showed $^{17}$ that in South Africa MS is rare in European white immigrants who migrated in childhood but more frequent if they entered South Africa after adolescence. While studying TSP patients in London over the past four years we have seen a number of AfroCaribbean patients who had MS and three with myelopathy of unknown cause.

The purpose of this paper is to compare the demographic, clinical and laboratory features of these patients of Afro-Caribbean descent with progressive myelopathies, mostly TSP, with those patients of similar extraction with MS. Secondly, we wanted to ascertain whether these data are consistent with current hypotheses concerning the importance of migration on the liability to develop MS.

\section{Methods}

All patients of Afro-Caribbean origin referred to the authors over the previous four years with a diagnosis of TSP, myelopathy of unknown cause or MS were reviewed. All but two were resident in the London area. The diagnostic criteria for MS used were the clinical ones of Poser et al, ${ }^{18}$ that is, clinically definite (CDMS A1), clinically probable (CDMS C1) or post-mortem diagnosis (proven MS). The diagnosis of TSP was made in those patients with a progressive myelopathy in the presence of at least one normal full length myelogram and evidence of HTLV-1 infection.

All patients were questioned and examined by the authors. HTLV-1 antibodies were sought in the blood and CSF by an ELISA and particle agglutination assay and western blotting $^{19}$ in all but two patients and the polymerase chain reaction (PCR) to detect integrated HTLV-1 genome using gag and $X$ region primers ${ }^{20}$ in 11 of the 27 patients with TSP and in four of the HTLV-1 antibody negative patients (three with MS). Visual, auditory and somato-sensory evoked potentials were recorded using standard techniques $^{21}$ and the CSF examined for total cell count, protein and IgG oligoclonal bands and for viral specific IgG and IgM antibodies. ${ }^{22}$ Nuclear MRI were obtained using a Picker 0.5 Tesla superconducting imager. Sections of the brain were made using a spin echo sequence (SE 2000/60) with $5 \mathrm{~mm}$, or occasionally $10 \mathrm{~mm}$, contiguous slices. The cervical cord was imaged using a saddle shaped coil and the dorsal cord examined using a planar coil. Contiguous $5 \mathrm{~mm}$ 
Table 1 Demographic data and HTLV-1 status of patients

\begin{tabular}{|c|c|c|c|c|c|c|c|c|}
\hline Diagnosis & $\begin{array}{l}\text { Number } \\
\text { of } \\
\text { patients }\end{array}$ & $\begin{array}{l}\text { HTLV-1 } \\
\text { positive }\end{array}$ & $\begin{array}{l}{ }^{\star \star} \text { Age } \\
(\text { mean } \\
\pm S D)\end{array}$ & $\begin{array}{l}\text { Sex } \\
(M / F)\end{array}$ & $\begin{array}{l}\text { Place of } \\
\text { birth } \\
\text { West-Indies }\end{array}$ & U.K. & $\begin{array}{l}\text { Time in } \\
\text { U.K. of } \\
\text { immigrant }\end{array}$ & $\begin{array}{l}\text { Duration of } \\
\text { disease } \\
\text { (mean } \pm S D)\end{array}$ \\
\hline $\begin{array}{l}\text { TSP } \\
\text { Other } \\
\text { progressive }\end{array}$ & 27 & 27 & $\star 54(8.4)$ & $3 / 24$ & 27 & 0 & $29 \cdot 4(4 \cdot 2)$ & $8.6(6.0)$ \\
\hline $\begin{array}{l}\text { progressive } \\
\text { paraparesis } \\
\text { MS }\end{array}$ & $\begin{array}{l}3 \\
14\end{array}$ & $\begin{array}{l}0 \\
0 \dagger\end{array}$ & $\begin{array}{l}30 \\
\star 38.0(11 \cdot 3)\end{array}$ & $\begin{array}{l}3 / 0 \\
2 / 12\end{array}$ & $\begin{array}{l}3 \\
9\end{array}$ & $\begin{array}{l}0 \\
5\end{array}$ & $\overline{27} \cdot 0(3 \cdot 0)$ & $\begin{array}{l}6 \cdot 6 \\
7 \cdot 4(5 \cdot 9)\end{array}$ \\
\hline
\end{tabular}

$\dagger 12 / 14$ tested.

${ }_{\star \star \star} \mathrm{p}<0.001$.

multislice images were made using a SE $500 / 40$ sequence to depict the anatomy and SE $1500 / 80$ to detect lesions with increased $T_{2}$ relaxation.

\section{Results \\ Patients}

Forty four patients of Afro-Caribbean origin were seen. Twenty seven of 30 patients with a progressive paraparesis had antibodies to HTLV-1 in their blood and all 11 of those studied had evidence of infection on PCR. These patients are classified here as having TSP. The remaining three patients were antibody negative, one of whom was also studied using PCR; this latter patient had no evidence of HTLV-1 infection. Fourteen patients had MS which was classified on clinical or necropsy criteria alone as proven (1), clinically definite [CDMS A1] (12), and clinically probable [CDMS C1] (1). None of the $12 \mathrm{MS}$ patients tested had antibodies to HTLV-1 (the three studied were negative on PCR). Relevant demographic data are shown in table 1.

Patients with TSP and patients with MS

The patients with MS were significantly younger than those with TSP but the duration of the disease was similar, as was the sex ratio, with a marked excess of females. All the patients with TSP were born in the Caribbean as were two thirds of those with MS. There was no difference in duration of residence in the UK of the migrant patients with TSP and MS (29.4 years versus 27.0 years). The mean age at which the migrants with MS entered the UK was 18.0 years (range 7-30 years, four aged 17 years or less). The mean age of onset of symptoms in these West Indian-born MS patients was $36 \cdot 6$ years compared with 19.8 years in the UKborn MS patients (table 2). Thus the time of residence in the UK before the first symptoms of MS was similar in the two groups viz: 19.8 years for the UK-born patients compared with $17 \cdot 6$ years for the West Indian-born patients.

All the patients with MS had clinical evidence of multiple lesions within the central nervous system including the optic nerve (8), brainstem (8), cerebellum (9), pyramidal (11)

Table 2 Demographic data on UK and Caribbean-born MS patients

\begin{tabular}{|c|c|c|c|c|}
\hline & Age & $\begin{array}{l}\text { Age at onset } \\
\text { of } M S\end{array}$ & $\begin{array}{l}\text { Duration of } \\
\text { disease }\end{array}$ & $\begin{array}{l}\text { Time in UK before } \\
\text { onset of disease }\end{array}$ \\
\hline $\begin{array}{l}\text { UK-born } \\
\text { Caribbean-born }\end{array}$ & $\begin{array}{c}\star 25.4(3.5) \\
43.4(11.0) \\
\mathrm{p}<\quad 0.001\end{array}$ & $\begin{array}{l}19.8(2.8) \\
36.6(9.8) \\
\mathrm{p}<0.001\end{array}$ & $\begin{array}{l}5.5(2.9) \\
8.7(6.5) \\
\text { NS }\end{array}$ & $\begin{array}{l}19 \cdot 8(2 \cdot 8) \\
17.6(7 \cdot 4) \\
\text { NS }\end{array}$ \\
\hline
\end{tabular}

^Mean (SD). and sensory tracts (8), and bladder pathways (10), and all had clear clinical evidence of one to seven relapses within one or more of these systems. The relapses and signs were typical of those found in other patients with MS including episodes of retrobulbar neuritis ( 3 patients) and signs such as bilateral internuclear ophthalmoplegia (3) or a deafferented hand (1). Five patients had entered a secondarily progressive phase and all but four of the entire series were moderately to severely disabled, one having died of multiple sclerosis (Kurtzke disability score of 5-10). These findings contrast with those of the TSP patients, all of whom had a progressive paraparesis with bladder involvement, with little evidence of upper limb abnormality and no clinical symptoms or signs of cranial nerve dysfunction. The disability was, however, similar in the two groups, all but five of the TSP patients requiring at least one cane for walking.

Evoked potentials in the visual (VEP), auditory (AEP) and median nerve somatosensory (SEP) areas were abnormal in both groups of patients (table 3). A similar proportion of abnormalities of the AEP $(30-40 \%)$ and SEP (50-70\%) were found in the TSP and MS patients. In contrast over $90 \%$ of the MS patients had abnormalities of the VEP compared with approximately $50 \%$ of the TSP patients, a significant difference $(p<0.05)$. Furthermore the abnormalities tended to be symmetrical in the TSP patients $(11 / 14)$ but were more often asymmetrical in those with MS (7/12), defining asymmetry as an interocular latency difference of $>12 \mathrm{~ms}$ or a unilateral abnormality $(p<0.06)$. Four MS patients had no consistently recorded VEP from one eye, a situation that never occurred in TSP, but the mean increase in latency (ignoring absent responses) was not greater in the patients with MS. SEPs from the lower limbs and central motor conduction times were not recorded in sufficient patients with MS to enable comparison with TSP.

The spinal fluid showed little difference between TSP and MS except in terms of local immunoglobulin synthesis. All the patients with TSP had oligoclonal bands (IgG) compared to only $50 \%$ of the MS patients. Further-

Table 3 Proportion (\%) of abnormal evoked potentials in TSP and MS patients

\begin{tabular}{llll}
\hline & $V E P$ & $A E P$ & $S E P$ \\
\hline MS & $92^{\star}$ & 33 & 50 \\
TSP & $54^{\star}$ & 42 & 68 \\
\hline${ }^{\star} \mathrm{p}<0.05$ & & &
\end{tabular}


Table 4 Abnormalities (\%) on MRI in MS and TSP

\begin{tabular}{llllllllll}
\hline & Cord & & & Brain & & & & \\
\cline { 2 - 7 } & Cervical & Dorsal & & Brainstem & Cerebellum & Corpus striatum & White matter & Periventricular & Any \\
\hline TSP & 0 & 60 & & 18 & 0 & 12 & 65 & $71(18) \dagger$ & 76 \\
MS & $80^{\star}$ & $\star \star$ & & 70 & 30 & 10 & 100 & $100(50) \dagger$ & 100 \\
\hline
\end{tabular}

$\star 4$ patients out of 5 .

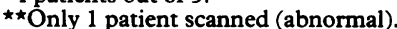

$\dagger(\%)$ with moderate or severe abnormality.

more in the seven TSP patients studied some of the bands contained IgG (5) or IgM (2) HTLV-1 specific immunoglobulins. In some TSP patients oligoclonal bands were found in the serum which never occurred in MS. The CSF protein was elevated in $73 \%$ of the MS patients and $39 \%$ of those with TSP, while there was a pleocytosis of greater than 5 cells $\mathrm{mm}^{-3}$ in $48 \%$ of the TSP patients and $36 \%$ of the MS patients. The typical HTLV-1 infected lymphocytes were not sought in the CSF in this study. Two MS patients in severe relapse had cell counts in excess of 100 cells $\mathrm{mm}^{-3}$ on one occasion, whereas no TSP patient had a pleocytosis in greater than 50 cells $\mathrm{mm}^{-3}$.

Ten of the 27 TSP patients had positive reagin and FTA tests for Treponemal infection in the blood and one patient with MS, who had previously had syphilis, was also positive. The CSF testing was negative in all patients. Those TSP patients with positive serology tended to be older than those with negative tests $(57.4$ years versus $52 \cdot 7$ years).

MRI of the brain was carried out in 12 patients with $\mathrm{MS}$ and 17 patients with TSP. All the MS patients and $75 \%$ of the TSP patients had an abnormal scan. There were, however, marked differences between the two groups (table 4). First, less than $20 \%$ of the TSP patients had abnormal signal return in the brainstem compared with $70 \%$ of the MS group. Secondly, the cerebellum was involved in $30 \%$ of the MS patients but was invariably spared in the TSP patients. Thirdly, periventricular lesions were always found in the MS patients and in half, the signal return,
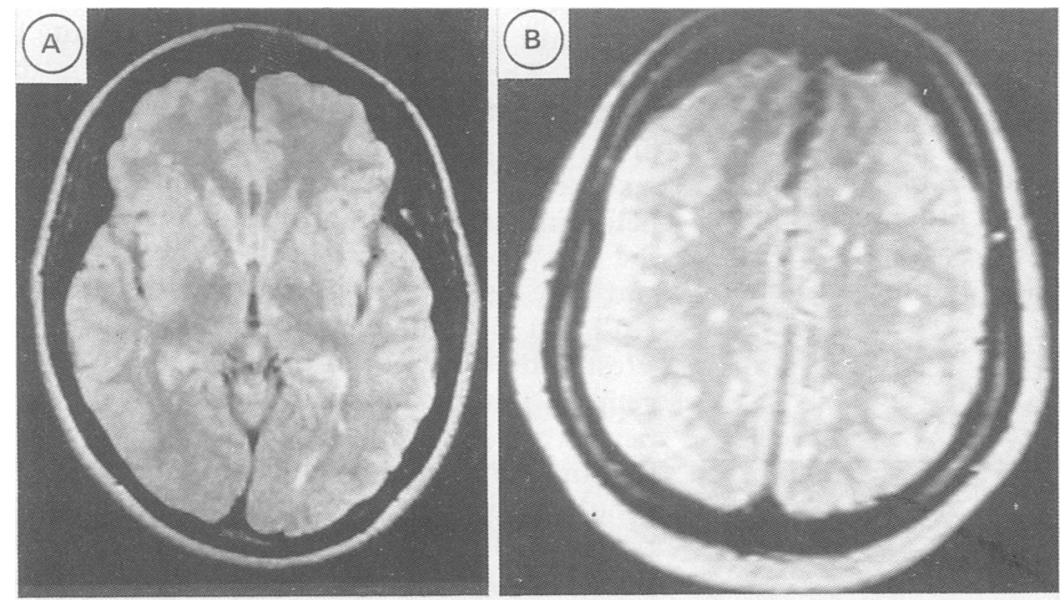

Figure 1 (a) $T_{2}$ weighted MRI showing multiple discrete lesions in cerebral hemisphere white matter in 44 year old MS patient. (b) $T_{2}$ weighted MRI showing multiple discrete lesions in cerebral hemisphere white matter in 65 year old patient with TSP. especially from the trigone and occipital horns, was markedly abnormal while in the TSP patients the changes were mild. Discrete lesions in the central white matter were invaribly found in patients with MS (fig la) but were seen in only two thirds of the TSP group. Finally, although not specifically studied, extensive abnormality of the corpus callosum was confined to the MS patients. It should, however, be emphasised that these differences in the MRI of patients with MS and those with TSP are relative, not absolute; three patients with MS had scans that were no more abnormal qualitatively or quantitatively than the most abnormal scans from TSP patients (compare fig 1 (a) and (b)).

Cervical cord scans were always normal in

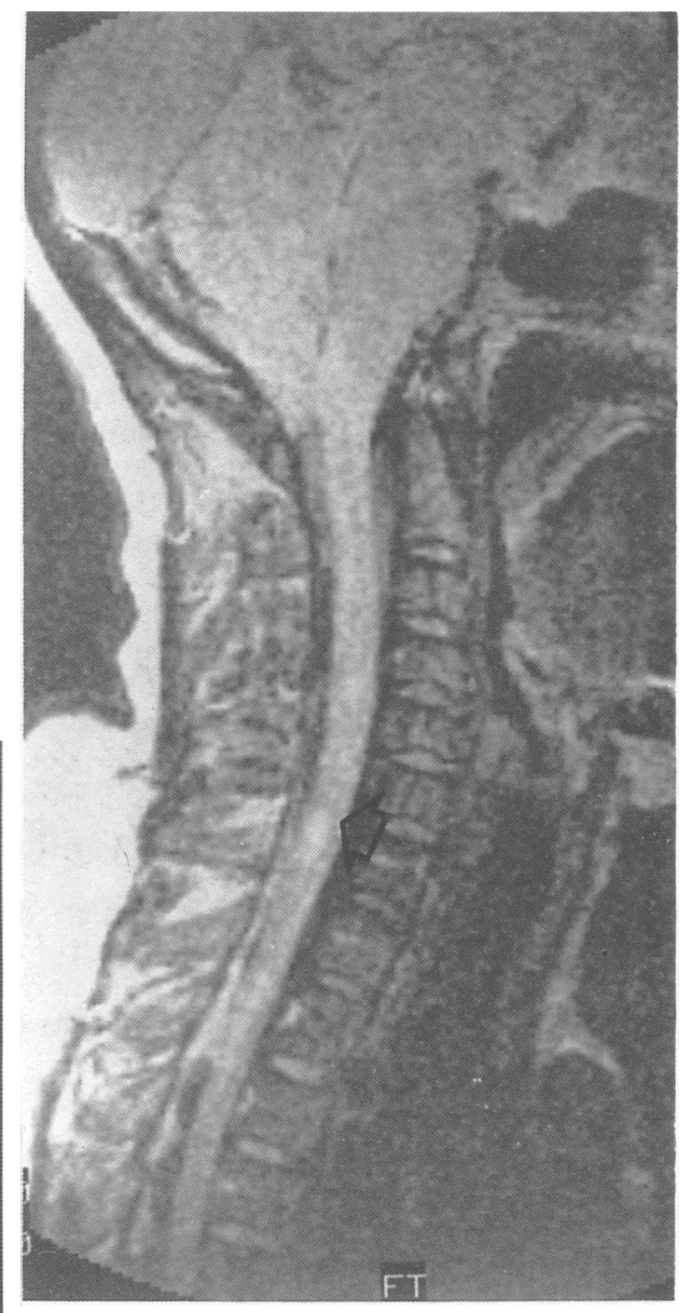

Figure $2 T_{2}$ weighted MRI of cervical cord in 47 year old patient with proven MS. Arrow indicates areas of focal signal return. There is also an equivocal area of increased signal return two segments higher. 

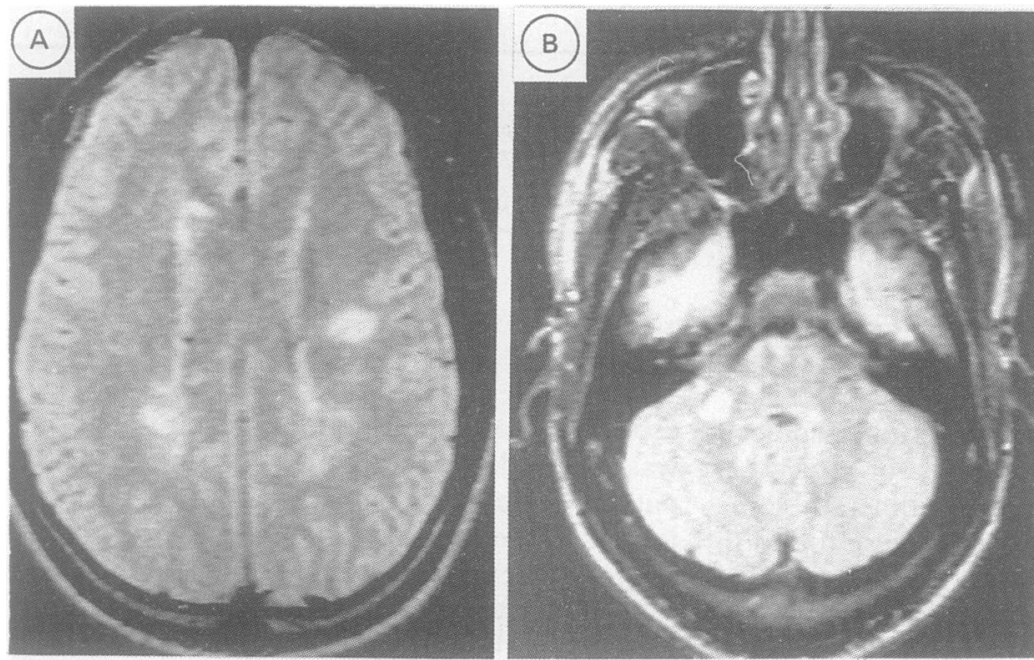

Figure 3 (a) $T_{2}$ weighted MRI of cerebral hemispheres in patient with HTLV-1 negative progressive paraparesis (case 1) showing large areas of increased signal return in the white matter and periventricular areas. (b) $T_{2}$ weighted MRI of posterior fossa from same patient showing areas of increased signal return in the middle cerebellar peduncle, cerebellar hemispheres and brainstem.

the TSP patients but four out of the five MS patients scanned, all of whom had clinical evidence of cervical cord disease, had abnormal cervical cords with one or more plaques apparent (fig 2). The dorsal cord was atrophic in $60 \%$ of the TSP patients and the signal return was either normal or diffusely increased with the exception of one patient where there was a focus of high signal return. As the dorsal cord was scanned in only one MS patient, and this showed focal increase in signal return, comparison with the TSP patients is not possible.

\section{HTLV-1 negative paraparesis}

Three patients with a provisional diagnosis of TSP were found not to have evidence of HTLV-1 infection (table 5). All had a paraparesis and this was progressive in two, but had remained static for more than 10 years in one. The MRI of the cord and the brain of the one born in the UK (case 1) showed extensive lesions in the cerebral hemispheres and discrete lesions in the posterior fossa of the type commonly seen in MS (fig 3 (a) and (b)). Case 2 had an MRI confined to the cervical and dorsal cord which showed diffusely abnormal signal return while case 3 was not studied.

\section{Discussion}

The differential diagnosis of progressive paraparesis, with or without other neurological symptoms, and normal myelography in AfroCaribbean subjects raises a number of important issues.

Table 5 HTLV-1 negative patients with paraparesis

\begin{tabular}{llllllll}
\hline Case & Age $(y)$ & Sex & Place of birth & $\begin{array}{l}\text { Duration of } \\
\text { illness }(y)\end{array}$ & VEP & & \multicolumn{2}{c}{ Cord } & Brain \\
\hline 1 & 25 & M & UK & 1.5 & A & A & A \\
2 & 45 & M & St. Lucia & 3.5 & N & A & N \\
3 & 58 & M & Jamaica & 15 & N & ND & ND \\
\hline
\end{tabular}

A-Abnormal; N-Normal; ND-Not done.
HTLV-1 antibody status

None of the 11 patients with MS who were tested had antibodies to HTLV-1 in their sera or CSF while all those with TSP by definition had such antibodies, usually in high titre. ${ }^{19224}$ There was no evidence on PCR that hidden integrated HTLV-1 was present in the genome of the patients with MS. These results support our previous studies on 44 white resident British and American patients and one AfroCaribbean patient with multiple sclerosis ${ }^{24}$ and those of Bangham et al ${ }^{25}$ and are counter to the results of Reddy et $a l^{26}$ and Greenberg et al. ${ }^{27}$ As has been previously argued ${ }^{24}$ it is thought that contamination of the assay system accounted for this discrepancy with Reddy et $a l^{26}$ while it is possible that Greenberg et $a l^{27}$ included some patients with TSP in their study.

There were three patients in our series who had a paraparetic illness with no evidence of HTLV-1 infection. The nosology of this small group is uncertain but it is possible that a small proportion of such patients have the slowly progressive paraparetic form of MS; case 1 of this group in our study may be an example since the MRI showed changes typical of MS rather than TSP. The other two remain undiagnosed.

\section{Place of birth}

Conventional wisdom, stemming from Dean's work, argues that patients of Afro-Caribbean origin who are resident in the UK and who have MS are usually born in the UK. The results described in this paper do not support this thesis. This discrepancy could well be due to selection bias of our cases as we have not surveyed an entire population. Dean et al in their surveys of MS in ethnic minorities in the $\mathrm{UK}^{14-16}$ did attempt full appraisal of hospital based cases within defined areas viz: London and the West Midlands. Two thirds of our MS patients, however, were born in the Caribbean and all but four emigrated after adolescence, that is, at 20 years or older. These MS patients, born outside the UK, were significantly older at the time their disease developed than those born in the UK (see table 2). However, the time of residence in the UK before developing symptoms was similar both in the Caribbeanborn and UK-born MS groups (about 18 years). These data are consistent with the concept that the agent that causes MS is found in the UK but not in the Caribbean and that it takes about 20 years of contact or incubation before the disease is apparent. Conversely, all the TSP patients were born in the Caribbean and the agent that causes the disease viz: HTLV-1, is endemic and widespread in the West Indies but not in the UK; it requires in general, but not invariably, a long incubation period before neurological disease occurs with this infection. If this concept is correct TSP should begin to appear in UK-born subjects, provided viral transmission occurs in this temperate area, but it may take decades to become apparent given the inefficiency of acquisition. Host factors may also be important in determining whether a patient of Afro-Caribbean 
origin develops MS or a white European presents with TSP but data presented here, and those of Dean, ${ }^{14-16}$ suggest that, as far as MS is concerned, environmental factors predominate over ethnic ones.

A further point of interest concerning MS in our Afro-Caribbean patients is the young age of onset in the UK-born subjects and the apparent severity of the disease. The mean age of onset in white populations is about 34 years compared with 20 years in our subjects born in the UK. Further, half of our patients, wherever they were born, were severely disabled within five to eight years, a proportion higher than expected from studies on white populations. ${ }^{28}$ While this may well be an accident of sampling it is tempting to interpret these data in terms of acquisition of a virus to which the population has never been exposed before; such an event commonly results in severe illness in humans and animals, for example, measles in Eskimaux, myxomatosis in rabbits. If this speculation is correct it supports the concept of geographical restriction of the agent causing MS but does not preclude genetic factors also being important.

\section{Certainty of the diagnosis of $M S$}

The diagnosis of MS in our patients seems secure on clinical and investigative grounds but in at least one patient a diagnosis of sarcoidosis was entertained. Sarcoidosis is common in patients of Afro-Caribbean extraction and can simulate MS. There was no positive evidence of sarcoidosis in 13 of the patients studied but in the remaining patient equivocal hilar lymphadenopathy on chest radiograph, and uncertain gallium lacrymal scan and Kveim test gave some support for the diagnosis. This patient, however, died and at necropsy lesions typical of MS were found throughout the spinal cord and brain and there was no abnormality suggesting sarcoidosis in any organ. Thus the diagnosis of sarcoidosis was not sustained.

The only other patient with MS who had another disorder that could have affected the CNS was the patient with a past history of syphilis. However, he had no evidence of CNS syphilis on serological testing, with negative CSF and no evidence of local specific immunoglobulin synthesis.

\section{Differentiation of MS from TSP}

Apart from the invariable occurrence, now by definition, of HTLV-1 antibodies (and the characteristic HTLV-1 leucocytes) in the blood of TSP patients and their absence in MS, in subjects of Afro-Caribbean extraction there are clinical and other laboratory features that separate the two conditions. In particular in MS the relapsing and remitting nature of the illness, clinical involvement of cranial nerves, the more extensive abnormalities on MRI including focal signal return in the posterior fossa structures and cervical cord, and the asymmetry of the VEP, are all features that are not common, or do not occur, in TSP. No clinical feature, however, other than the relapsing and remitting course, is confined to the MS group and many features such as the CSF abnormalities and derangement of the AEP and SEP are similar in the two conditions. The final arbiter of the diagnosis of TSP against MS is the HTLV-1 status of the patient bearing in mind the small proportion (probably $<2 \%$ ) of Afro-Caribbean subjects who carry HTLV-1 in the UK. In general, the serum titres of HTLV-1 are high and some of the oligoclonal bands in the CSF are directed against HTLV-1 antigen in TSP, while asymptomatic but infected individuals usually have low serum titres. This makes the detection of HTLV-1 antibodies in high titre in a symptomatic subject fairly secure grounds on which to base a diagnosis of TSP.

The certainty of diagnosis of MS versus TSP is relevant to epidemiological surveys particularly those involving small numbers of patients as in the case of MS in immigrants from the West Indies to the UK. To date HTLV-1 status has not been used fully to screen patients in these surveys, including the most recent, but two of the TSP (HTLV-1 positive) patients in our study were identified as having been included in the $1976 \mathrm{MS}$ in the immigrants survey by Dean ${ }^{16}$ and to whom the diagnosis of MS was attached in the hospital notes at the time. If a substantial proportion of patients in that survey were wrongly classified, and some did have a progressive paraparesis, MS would have been even rarer in the immigrants than originally suggested. This makes our results, albeit from a selected population, all the more surprising.

\section{Treponemal infection}

There has been considerable debate over the high prevalence of positive Treponemal serology in TSP. About one third of the series described by Cruickshank et $a l^{2}$ in the 1960 s had positive Treponemal serology in the blood and a similar proportion of our patients were positive. None, however, had positive serology for Treponemal infection in the CSF. Further, all our patients who had positive reagin tests also had positive fluorescent Treponemal antibody (FTA) tests implying that the antibodies were Treponeme specific. Yaws acquired in the Caribbean is the most likely explanation for this positivity; syphilis is also common in the West Indies and might contribute to the high prevalence of positive specific Treponemal serological tests in TSP patients as it does in the Seychelles ${ }^{8}$ where yaws does not occur but the rate of FTA positivity in the general population is similar to that in the local TSP group. In contrast, only one of the MS patients born in the Caribbean was FTA positive and he had a good history of previous syphilitic infection.

Why should there be this difference between TSP and MS in terms of FTA positivity? One explanation is that the Caribbean-born MS patients were 10 years younger than the TSP patients and there is good evidence that yaws has disappeared in the past 20 years in the Caribbean (personal communication, Dr Winston Chen, University of the West Indies). Thus it is quite possible that the TSP patients did contract yaws at a time when the condition 
was highly endemic but the younger MS patients did not have the opportunity to acquire the disease. The fact that those patients with TSP who had positive Treponemal serology were older than those without such antibodies favours this hypothesis. Whatever the explanation, the fact that the FTA is positive in all cases with a positive VDRL excludes the possibility that an epitope common to the lipid of the reagin test and the envelope of HTLV-1 is responsible for the high prevalence of positive Treponemal serology in TSP.

This survey has shown that MS occurs not only in Afro-Caribbean patients born in the UK but also in those who have emigrated from the West Indies and that some of these patients did not leave their native country until well after attaining sexual maturity. We have also shown that most patients with MS can be distinguished clinically and on magnetic scanning from TSP patients. Finally, HTLV-1 positivity is not found in the MS cohort but is extremely common in those patients with a progressive paraparesis without demonstrable cause thus defining a major subgroup, now known as TSP.

We thank the clinicians who referred patients to us and the Multiple Sclerosis Society of Great Britain and Northern
Ireland for their generous support of the MRI facility. We are Ireland for their generous support of the MRI facility. We are
also indebted to Drs A G Dalgleish and J H Richardson for their also indebted to Drs A G Dalgleish and J H Richardson for their
assistance in determining the HTLV-1 status of some of the assistance in determining the HTLV-1 status of some of
patients and donation of bench space in their laboratories.

1 Gessain A, Barin F, Vernant JC, Gout O, Maurs L, Calender $A$, de The $G$. Antibodies to human T-lymphotropic virus type 1 in patients with tropical spastic paraparesis. Lancet 1985;ii:407-9.

2 Montgomery RD, Cruickshank EK, Robertson WB, McMenemey WH. Clinical and pathological observations in Jamaican neuropathy. Brain 1964;87:425-62.

3 Morgan O St C, Montgomery RD, Rodgers-Johnson P. The myeloneuropathies of Jamaica. $Q J$ Med 1988;67:273-81.

4 Zaninovic V, Arango C, Biojo R, et al. Tropical spastic paraparesis in Colombia. Ann Neurology 1988;23;(suppl)S paraparesis 127 .

5 Iwasaki Y. Pathology of chronic myelopathy associated with HTLV-1 infection (HAM/TSP). I Neurolog Sci 1990; 96:103-23.

6 Kayembe K, Goubau P, Desmyter J, Vlietinck R, Carton H. A cluster of HTLV-1 associated tropical spastic paraparesis in Equateur (Zaire): ethnic and familial distribution. J Neurol Neurosurg Psychiatry 1990;53:4-10.
7 Bhigiee AI, Kelbe C, Haribhai HC, et al. Myelopathy associated with human $T$ cell lymphotropic virus type 1 (HTLV-1) in Natal, South Africa. A clinical and inves-

8 Roman GC, Spencer PS, Schoenberg BS, et al. Tropical spastic paraparesis in the Seychelles Islands. Neurology 1987;37:1323-8.

9 Gout O, Gessain A, Bolgert F, et al. Chronic myelopathies associated with human T lymphotropic virus type 1. Arch Neurol 1989;46:255-60.

10 Newton M, Cruickshank JK, Miller D, et al. Antibody to human T-cell lymphotropic virus type 1 in West Indianborn UK residents with spastic paraparesis. Lancet 1987;1:415-6.

11 Cruickshank JK, Rudge P, Dalgleish AG, et al. Tropical spastic paraparesis and human $T$ cell lymphotropic virus spastic paraparesis and human 1

12 Cruickshank EK, Montgomery RD. Multiple sclerosis in Jamaica. West Indian Medical Journal 1961;10:211.

13 Williams ES, McKeran RD. Prevalence of multiple sclerosis in a south London borough. $B M J 1986 ; 2: 237-9$.

14 Elian M, Dean G. Multiple sclerosis among the United Kingdom-born children of immigrants from the West Indies. J Neurol Neurosurg Psychiatry 1987;50:327-32.

15 Elian M, Nightingale S, Dean G. Multiple sclerosis among United Kingdom born children of immigrants from the Indian sub-continent, Africa and the West Indies. Neurol Neurosurg Psychiatry 1990;53:906-11.

16 Dean G, McLoughlin H, Brady R, Adelstein A, TallettWilliams J. Multiple sclerosis among immigrants in Greater London. BMJ 1976;1:861-4.

17 Dean G. Annual incidence, prevalence and mortality of multiple sclerosis in white South African-born and white immigrants to South Africa. $B M J$ 1967;2:724-30.

18 Poser CM, Paty DW, Scheinberg L, et al. New diagnostic criteria for multiple sclerosis: guidelines for research criteria for multiple sclerosis: guidel

19 Dalgleish A, Richardson J, Matutes E, et al. HTLV infection in tropical spastic paraparesis: lymphocyte culture and serological response. AIDS and Human Retro viruses 1988;4:475-85.

20 Cruickshank JK, Richardson JH, Morgan O St C, et al. Screening for prolonged incubation of HTLV-1 infection in British and Jamaican relatives of British patients with tropical spastic paraparesis. $B M J 1990 ; 300: 300-4$.

21 Halliday AM, ed. Evoked potentials in clinical testing. Edinburgh: Churchill-Livingstone, 1982.

22 McLean BN, Rudge P, Thompson EJ. Viral specific IgG and IgM antibodies in the CSF of patients with tropical spastic IgM antibodies in the CSF of patients with

23 Link H, Cruz M, Gessain A, Gout O, de The G, KaraHansen S. Chronic progressive myelopathy associated with HTLV-1. Neurology 1989;39:1566-72.

24 Richardson JH, Wucherpfennig KW, Endo N, Rudge P, Dalgleish AG, Hafler DA. PCR analysis of DNA from multiple sclerosis patients for the presence of HTLV-1. Science 1989;246:821-3.

25 Bangham CRM, Nightingale S, Cruickshank JK, Daenke S. PCR analysis of DNA from multiple sclerosis patients for the presence of HTLV-1. Science 1989;246:821.

26 Reddy EP, Sandberg-Wollheim M, Mettus RV, Phillip ER, Defreitas E, Kaprowski H. Amplification and molecular cloning of HTLV-1 sequences from DNA of multiple cloning of $\mathrm{H}$ (erosis patients. Science 1989;243:529:33.

27 Greenberg SJ, Ehrlich GD, Abbott MA, Hurwitz BJ, Waldmann TA, Poiesz BJ. Detection of sequences Waldmann TA, Poiesz BJ. Detection of sequences homologous to human retroviral DNA in multiple sclerosis by ge

28 Confavreux C, Aimard G, Devic M. Course and prognosis of multiple sclerosis assessed by computerised data processing of 349 patients. Brain 1980;103:281-300. 